\title{
Intratumoral Gene Expression of Dihydrofolate Reductase and Folylpoly-C-Glutamate Synthetase Affects the Sensitivity to 5-Fluorouracil in Non-Small Cell Lung Cancer
}

\section{Kayo Sakon ( $\nabla$ ksakon@u-fukui.ac.jp )}

University of Fukui, Faculty of Medical Sciences

\section{Masato Sasaki}

University of Fukui, Faculty of Medical Sciences

Kaede Tanaka

University of Fukui, Faculty of Medical Sciences

Tae Mizunaga

University of Fukui, Faculty of Medical Sciences

\section{Keita Yano}

University of Fukui, Faculty of Medical Sciences

\section{Yuiko Kawamura}

University of Fukui, Faculty of Medical Sciences

\section{Akitoshi Okada}

University of Fukui, Faculty of Medical sciences

\section{Takeshi lkeda}

National Center for Global Health and Medicine

\section{Sawaka Tanabe}

University of Fukui, Faculty of Medical Sciences

\section{Atsushi Takamori}

University of Fukui, Faculty of Medical Sciences

Narihisa Yamada

University of Fukui, Faculty of Medical Sciences

Kouichi Morioka

University of Fukui, Faculty of Medical Sciences

Takaaki Koshiji

University of Fukui, Faculty of Medical Sciences

Research 
Keywords: histoculture drug response assay, reverse-transcriptase polymerase chain reaction, thymidylate synthase, dihydropyrimidine dehydrogenase, orotate phosphoribosyltransferase

Posted Date: March 19th, 2021

DOI: https://doi.org/10.21203/rs.3.rs-332802/v1

License: (1) This work is licensed under a Creative Commons Attribution 4.0 International License. Read Full License 


\section{Abstract}

Background: Various factors related to the sensitivity of non-small cell lung carcinoma (NSCLC) to 5fluorouracil (5-FU) have been reported, and some of them have been clinically applied. In this singleinstitutional prospective analysis, the mRNA expression level of five folic acid-associated enzymes was evaluated in surgical specimens of NSCLC. We investigated the correlation between the antitumor effect of 5-FU in NSCLC using an anticancer drug sensitivity test and the gene expression levels of five enzymes.

Materials and Methods: Forty patients who underwent surgery for NSCLC were enrolled, and the antitumor effect was measured using an in vitro anticancer drug sensitivity test (histoculture drug response assay) using freshly resected specimens. In the same sample, the mRNA expression levels of five enzymes involved in the sensitivity to 5-FU were measured in the tumor using real-time PCR. The expression levels and the result of the sensitivity test were compared.

Results: No correlation was found between dihydropyrimidine dehydrogenase (DPD), orotate phosphoribosyltransferase (OPRT), or DPD/OPRT expression and the antitumor effects of 5-FU. On the other hand, a correlation was found between thymidylate synthase (TS), folylpoly-c-glutamate synthetase (FPGS), and dihydrofolate reductase (DHFR) expression and 5-FU sensitivity.

Conclusion: Expression of FPGS and DHFR may be useful for predicting the efficacy of 5-FU-based chemotherapy for NSCLC.

\section{Introduction}

5-fluorouracil (5-FU) is an antimetabolite that is widely used to treat various solid cancers including nonsmall cell lung cancer (NSCLC).1,2 In Japan, an oral 5-FU prodrug has been developed. 5 -fluorouracil (5-FU) is an antimetabolite that is widely used to treat various solid cancers including nonsmall cell lung cancer (NSCLC). ${ }^{1,2}$ In Japan, an oral 5-FU prodrug has been developed. At present, UFT ${ }^{\circledR}$ and TS-1 $\circledast$ are indicated in Japan for NSCLC and are often used as one of the drugs in postoperative adjuvant chemotherapy or systemic chemotherapy. ${ }^{3,4}$ Despite various measures to enhance the effects of $5-\mathrm{FU}$, the treatment is ineffective in many patients. In addition, 5-FU anticancer agents are less effective in patients with advanced or recurrent NSCLC. ${ }^{2}$ However, if the therapeutic effect of 5-FU anticancer drugs in cancer patients can be predicted before administration, the disadvantages of unnecessary administration can be prevented. Thus, identification of factors that can predict the effect of drugs before drug administration is important.

Several reports of NSCLC cases have described the sensitivity to 5 -FU using clinical samples, ${ }^{5-7}$ but no clear findings have been obtained. In this study, the level of mRNA expression of factors associated with 5-FU sensitivity (thymidylate synthase (TS), dihydropyrimidine dehydrogenase $(D P D)$, orotate phosphoribosyltransferase (OPRT), dihydrofolate reductase (DHFR), and folylpoly-c-glutamate synthetase 
(FPGS)) was measured with reverse-transcriptase polymerase chain reaction (RT-PCR), and we used the histoculture drug response assay (HDRA) method to assess sensitivity to 5-FU. We then investigated the correlation between the expression level of each factor and the chemosensitivity result.

\section{Patients And Methods}

\section{Patients}

Tissue samples were collected at the time of surgery from 40 patients who underwent surgery at the Department of Surgery (II), University of Fukui Hospital for NSCLC with a tumor size $>20 \mathrm{~mm}$ between January 2012 and December 2015. The experimental use of the chemosensitivity test was approved by the Institutional Research Committee, and the study was approved by the Ethics Committee of our institution. All patients were informed of the nature of this study, and written informed consent was obtained.

Fresh specimens were sampled from the primary lesion immediately after surgical resection, immersed in Hank's solution, and used for in vitro chemosensitivity testing with HDRA. Ten-micrometer-thick slices from the paraffin-embedded specimens were later used for quantitative RT-PCR.

\section{HDRA}

The HDRA was used as an in vitro drug sensitivity test as previously reported. ${ }^{8,9}$ Collagen sponge gels (Gel foam ${ }^{\circledR}$ ) manufactured from pig skin were purchased from Pfizer Japan Inc. (Tokyo, Japan). Cancerous portions of specimens were minced into pieces of approximately $10 \mathrm{mg}$, which were then placed on the prepared collagen surface in 24-well microplates. Plates were incubated for 7 days in the presence of drugs dissolved in RPMI 1640 medium containing 20\% fetal calf serum in a humidified atmosphere containing $95 \%$ air $/ 5 \% \mathrm{CO}_{2}$ at $37^{\circ} \mathrm{C}$. 5-FU was provided by Tokyo Chemical Industry Co. Ltd. (Tokyo, Japan) and used at $300 \mu \mathrm{g} / \mathrm{ml}$. After these specimens were histocultured, $100 \mu \mathrm{l}$ Hank's balanced salt solution containing $0.1 \mathrm{mg} / \mathrm{ml}$ type I collagenase (Sigma) and $100 \mu \mathrm{l} 9.6 \mathrm{mg} / \mathrm{ml}$ 3-(4,5dimetylthiazol-2-yl)-2,5-diphenyl tetrazolium bromide (MTT) solution dissolved in phosphate-buffered saline were added to each culture well and incubated for another $16 \mathrm{~h}$. Following extraction with dimethysulfoxide, absorbance of the solution in each well was read at $540 \mathrm{~nm}$ (control $630 \mathrm{~nm}$ ) using a microplate reader (Spectra Max M5; Molecular Device LLC, San Jose, CA). Absorbance per gram of cultured tumor tissue (OD/W) was calculated from the mean absorbance of tissue from three culture wells. The tumor tissue weight was determined prior to culture.

The inhibition rate was calculated using the following formula:

Inhibition rate $(\%)=(1-$ mean OD/W of treated well/mean OD/W of control well $) \times 100$

\section{Laser-capture microdissection and real-time RT-PCR (the Danenberg tumor profile [DTP] method)}


The quantitative assay of the five genes of interest (TS, DPD, OPRT, DHFR, and FPGS) using paraffinembedded sections of resected NSCLC specimens was performed according to the DTP method of Response Genetics (New York, NY, USA).$^{10}$ For every specimen, four sets of $10-\mu \mathrm{m}$-thick sections and one set of 5 - $\mu \mathrm{m}$-thick sections were prepared from formalin-fixed, paraffin-embedded tissues. The 5 - $\mu \mathrm{m}$-thick sections were stained with hematoxylin and eosin and examined histologically. The 10- $\mu$ m-thick sections were stained with nuclear fast red (American Master Tech Scientific, Lodi, CA) and used for laser-capture microdissection (PALM Microsystem, Leica, Wetzlar, Germany) from the upper and lower thirds of tumors, separately. The dissected tissue samples were transferred to reaction tubes containing $400 \mu \mathrm{l}$ RNA lysis buffer, and RNA was isolated. Finally, cDNA was prepared as described by Lord et al. ${ }^{11,12}$

Quantification of the five genes of interest (TS, DPD, OPRT, DHFR, and FPGS) and an internal reference gene ( $\beta$-actin) was performed using a fluorescence-based real-time PCR system (ABI PRISM 7900 Sequence Detection System, Applied Biosystems, Foster City, CA). The final volume of the reaction mixture was $20 \mu \mathrm{l}$. Cycling conditions and the primers and probes were described previously by Matsubara et al.13 Gene expression was analyzed twice to confirm the reproducibility, and values (relative mRNA levels) were expressed as the ratio between the gene of interest and the internal reference gene ( $\beta$-actin).

\section{Examination of the necessity of Gimeracil (5-chloro-2, 4-dihydroxypyridine (CDHP))}

NSCLC has high DPD activity ${ }^{14}$ and requires the use of CDHP, an inhibitor of DPD. In an anticancer sensitivity test, the sensitivity effect of adding CDHP was also examined. Previous experiments were performed to determine the appropriate concentration of CDHP. The experiment was performed by dividing 5-FU alone into four groups at a concentration obtained by adding $200 \mu \mathrm{g} / \mathrm{ml}$ and $300 \mu \mathrm{g} / \mathrm{ml}$ $\mathrm{CDHP}$ to $200 \mu \mathrm{g} / \mathrm{ml}$ and $300 \mu \mathrm{g} / \mathrm{ml}$ 5-FU. At that concentration, 5-FU was used in combination with CDHP, and the results were observed.

\section{Statistical analysis}

Statistical analysis was performed on a personal computer with Stat Mate IV (Ver. IV, ATMS, Japan). The correlations between the mRNA expression of genes examined and clinico-pathological parameters were evaluated with the Pearson product moment correlation coefficient. To evaluate the correlation between two variables, linear regression was performed, and the Spearman rank correlation coefficient was calculated. Probability $(P)$ values of less than 0.05 were considered statistically significant.

\section{Results}

\section{Anticancer sensitivity test (HDRA) for 5-FU in our institution}

The anticancer drug sensitivity test for 5-FU in NSCLC has been conducted in our department since 2006, and HDRA at the relevant 5-FU concentration of $300 \mu \mathrm{g} / \mathrm{ml}$ was successfully performed for 419 patients (289 males and 130 females, median age 71.3 years, range 39-82 years). 


\section{Examination of the necessity of CDHP}

A test was conducted to examine the results of sensitivity to 5-FU by changing the concentration of CDHP in 29 cases of NSCLC. We found no significant difference in sensitivity between the 5-FU only group (suppression rate $62 \pm 17 \%, \mathrm{n}=29$ ) and the group to which CDHP was added (300 mg; $60 \pm 18 \%, \mathrm{n}=29$, $200 \mathrm{mg} ; 60 \pm 17 \%, \mathrm{n}=23$ ). Therefore, this study was performed using only 5-FU. We also examined the toxicity of CDHP by performing a CDHP alone sensitivity test without 5-FU. CDHP alone showed a very low inhibition rate and no antitumor effect $(8 \pm 10 \%, n=29)$.

\section{Patient characteristics}

Forty patients (29 men (72.5\%) and 11 women (27.5\%)) who underwent surgery at our hospital for NSCLC were enrolled (Table 1). The median age was 70 years (range, 47-84 years). The postoperative pathological stage was stage IA in 10 patients (25\%), stage IB in nine (22.5\%), stage IIA in 10 (25\%), stage IIB in four (10\%), stage IIIA in five (12.5\%), and stage IV in two (5\%).

The operative procedure was lobectomy in 35 patients (87.5\%), segmental resection in two patients (5\%), and partial wedge lung resection in three patients (7.5\%). The histology included 23 cases of adenocarcinoma (57.5\%), 15 cases of squamous cell carcinoma (37.5\%), and two cases (5\%) of other types of NSCLC. Regarding EGFR mutation and ALK translocation in adenocarcinoma, seven cases were L858R positive, three cases were exon 19 positive, one case was $A L K$ positive, and 12 cases were wild type (Table 1).

\section{Comparison of gene expression and the percent inhibition in the anticancer sensitivity test (HDRA) for 5-} FU

Gene expression of TS, OPRT, DPD, FPGS, and DHFR was successfully measured in 39, 39, 40, 40, and 40 specimens, respectively. The mean levels of mRNA of TS, OPRT, DPD, FPGS, and DHFR in these specimens were $3.690 \pm 2.663(n=38), 0.515 \pm 0.413(n=37), 1.200 \pm 0.637(n=39), 0.782 \pm 0.313(n=$ $39)$, and $1.700 \pm 0.930$ ( $\mathrm{n}=39) \mathrm{ng} / \mathrm{mg}$ of protein, respectively. Expression of these genes was not correlated with the age, sex, histopathological type, or clinical stage. We found no significant correlation between expression of DPD, OPRT, or DPD/OPRT and the percent inhibition with 5-FU using the HDRA method (Figure 1).

We found a significant correlation between expression of TS, FPGS, and DHFR and the percent inhibition with 5-FU using the HDRA method $(p<0.05, r=0.350, p<0.01, r=0.418$, and $p<0.05, r=0.331$, respectively) (Figure 2).

\section{Discussion}

To the best of our knowledge, this is the first study to show a correlation between FPGS and DHFR expression and 5-FU sensitivity results in NSCLC. FPGS showed a stronger correlation with 5-FU sensitivity than DHFR. 
FPGS converts intracellular folic acid and folic acid antagonists, such as methotrexate, into polyglutamic acid, which is retained intracellularly for a long time. Polyglutamylation of intracellular 5,10methylenetetrahydrofolate enables more efficient formation and stabilization of inhibitory ternary complexes involving TS and metabolites of $5-\mathrm{FU}$, and it may also increase the cytotoxicity of $5-\mathrm{FU} .{ }^{15}$ Two reports have shown a correlation between 5 -FU sensitivity and FPGS in colon cancer ${ }^{15}$ and breast cancer. $^{16}$

DHFR is the target enzyme of methotrexate, which enters the cell, tightly binds to DHFR, and inhibits the reduction of dihydrofolate to tetrahydrofolate. ${ }^{17}$ Only one report has evaluated the activity of DHFR and the antitumor effect of $5-F U .{ }^{18}$ They reported that DHFR mRNA had a high value using a 5 -FU-resistant mouse cell line.

5-FU is activated only after it is converted to 5-fluorodeoxyuridine monophosphate (FdUMP). TS, an enzyme that is essential for DNA synthesis, methylates deoxyuridine monophosphate (dUMP) and converts it to deoxythymidine monophosphate (dTMP). Therefore, FdUMP is covalently bonded to TS together with 5,10-methylenetetrahydrofolate (5,10-CH2-THF), which is reduced to folic acid, to form a strong ternary complex consisting of dTMP and deoxythymidine triphosphate (dTTP), which inhibits DNA synthesis. ${ }^{19}$ FPGS acts on the pathway that converts 5,10-CH2-THF from monoglutamate to polyglutamates, the increase in which is indispensable for creating a ternary complex that may affect the sensitizing effect of 5-FU. The function of TS activity is inhibition, and the pool of dTTP, which is a precursor of DNA, is depleted, leading to inhibition of DNA synthesis and cell death. ${ }^{19}$

In this study, the positive correlation between TS expression and 5-FU sensitivity is the opposite of the results of other reports of NSCLC. ${ }^{50-22}$ Regarding the sensitivity of TS in gastric cancer and colorectal cancer, sporadic reports have shown no correlation or reverse correlation between the sensitivity to 5-FU and increased TS activity. ${ }^{23,} 24$ In NSCLC, a positive correlation with TS was reported, but TS activity tends to be lower than in other carcinomas, ${ }^{14}$ suggesting that even if TS activity is high, it falls within the range where the effect of 5-FU can be observed.

Regarding the sensitivity of 5-FU, the activities of OPRT and DPD have been well evaluated, and several reports show that they are involved in the sensitivity of NSCLC. ${ }^{25-27}$ The results of this study did not show a correlation between OPRT and DPD expression and 5-FU sensitivity. Although the OPRT/DPD ratio has been reported to be an important predictor of the efficacy of fluoropyrimidine-based chemotherapy for metastatic colorectal cancer, ${ }^{25}$ this report on DPD/OPRT showed no significant difference with the sensitivity of 5-FU.

Several reports have described the relationship between $T S, D P D$, and $O P R T$ and 5-FU sensitivity in NSCLC. Eguchi et al. ${ }^{20}$ evaluated the relationship between response to treatment and immunohistochemical expression levels in patients with advanced NSCLC. Low expression levels of DPD and TS were seen in patients not treated with S-1-carboplatin, which is associated with better response 
and longer survival in patients treated with paclitaxel-carboplatin. Tumor expression levels of TS and DPD predict the response to S-1-carboplatin chemotherapy in patients with advanced NSCLC. Nakano et al. ${ }^{21}$ reported an immunohistochemical study on the clinical importance of TS, OPRT, and DPD expression using 151 NSCLC specimens resected from patients treated postoperatively with tegafur/uracil (UFT). Patients who had tumors with low TS expression $(p=0.0133)$, high OPRT expression $(p=0.0145)$, or low DPD expression $(p=0.0004)$ had significantly high of 5 -year survival rates. Shintani et al. ${ }^{5}$ investigated patients using RT-PCR for intratumoral expression and examined the correlation between gene expression and the efficacy of 5-FU in NSCLC. Patients receiving postoperative 5-FU alone $(n=30)$ comprised the 5FU group, and those who had only surgery were included in the control group $(n=86)$. When dichotomized by mean TS and DPD mRNA levels, patients with low DPD tumors receiving 5-FU had significantly better prognosis than those who did not receive adjuvant treatment $(p=0.041)$. Based on these results, quantification of TS and DPD mRNA levels can predict the efficacy of 5-FU after surgery in patients with NSCLC.

5-FU is rapidly degraded by DPD. Due to the higher DPD activity in NSCLC compared to other carcinomas, ${ }^{14}$-FU alone is less effective, necessitating co-administration of CDHP, for which S-1 was developed. In view of the mechanism of action of 5-FU, the effects of 5-FU are expected to be reduced if expression of the target enzyme TS and the degrading enzyme DPD in tumor tissue is high. CDHP (Gimeracil), which is used in S-1, ${ }^{28}$ inhibits DPD. In this study, we found no difference in the sensitivity results even if CDHP was added to 5-FU in the preliminary sensitivity test. This suggests that DPD may not affect the antitumor effect of 5-FU in vitro.

There are several reports that The HDRA method correlates well with the susceptibility of NSCLC to anticancer drugs and its clinical efficacy. ${ }^{29-31}$ Further, the usefulness of HDRA has been documented for several other cancer types including gastric cancer ${ }^{32}$ and colorectal cancer. ${ }^{33}$ This histo-culture method has the advantage of culturing cancer cells while maintaining cell-cell contacts which has good cell viability, and the disadvantage of requiring a certain amount of tissue sample. In the present study, sufficient amount of sample could be obtained from the surgical specimens. Moreover, the high evaluability rate $(n=419,96.5 \%)$ from previous tests for NSCLC conducted at our institution demonstrate that this method is a good alternative for testing the sensitivity of 5-FU in NSCLC.

The limitations of this study are the small number of cases, the single-institution design, and the in vitro results of the anticancer drug sensitivity test. Further clinical studies are needed. In the future, studying the relationship between anticancer effects in NSCLC patients who actually received 5-FU and the expression levels of various factors in the tumors is necessary. Another limitation is the in vitro use of specimens obtained during surgery. For unresectable advanced NSCLC, small specimens such as those obtained from bronchoscopy should be used. The feasibility of such transbronchial lung biopsy samples is being investigated. Nakajima et al. ${ }^{34}$ used a metastatic lymph node sample obtained with endobronchial ultrasound-guided transbronchial needle aspiration in patients with non-small cells to obtain 
$T S, D P D, T P$, and $O P R T$ mRNA. The feasibility of expression analysis should be evaluated. Clinical application is also expected.

Few reports have examined the sensitivity of 5-FU in NSCLC. Our study provides results that will be useful for assessing the sensitivity of 5-FU in future clinical applications.

\section{Conclusion}

The mRNA levels of five folic acid-associated enzymes involved in the antitumor effect of 5-FU were examined in resected NSCLC tumor specimens with RT-PCR, and the in vitro anticancer sensitivity test was performed. In conclusion, FPGS and DHFR may be involved in 5-FU sensitivity.

Previous studies have reported that TS, OPRT, and DPD are associated with 5-FU sensitivity. Combined with this result, the folic acid metabolism pathway is also important, and it will be the basis for the development of new anticancer agents using both pathways.

\section{Abbreviations}

HDRA; Histoculture Drug Response Assay, DPD; dihydropyrimidine dehydrogenase, OPRT; orotate phosphoribosyltransferase, TS; thymidylate synthase, CDHP; 5-chloro-2,4-dihydroxypyridine, RT-PCR; reverse-transcriptase polymerase chain reaction, NSCLC; non-small cell lung carcinoma, 5-FU; 5fluorouracil, FPGS; folylpoly-c-glutamate synthetase, DHFR; dihydrofolate reductase, FdUMP; 5fluorodeoxyuridine monophosphate, dUMP; deoxyuridine monophosphate, dTMP; deoxythymidine monophosphate, dTTP; deoxythymidine triphosphate, 5,10-CH2-THF; 5,10-methylenetetrahydrofolate

\section{Declarations}

\section{Acknowledgement}

The authors are indebted to Mio Kawakami for support as an excellent laboratory assistant.

\section{Authors' contributions}

K Sakon, M Sasaki, A Okada and T Ikeda are the attending physicians for these cases. K Sakon is responsible for the concept and design of this study, and everything. The other co-authors contributed to the acquisition and interpretation of the reference. K Sakon drafted the study and other co-authors revised it. All authors approve the publication of the manuscript and agree to take responsibility. All authors reviewed, edited, and agreed on the final draft of the manuscript.

\section{Funding}

This research did not receive any specific grant from funding agencies in the public, commercial, or notfor-profit sectors. 
Availability of data and materials

The dataset is available upon request.

\section{Ethics approval and consent to participate}

The ethics review board of University of Fukui Hospital approved this study. Written informed consent was obtained from the patient for extracting his data from electronic medical chart system. A copy of the written consent is available for review by the Editor-in-Chief of this journal on request.

\section{Consent for publication}

All authors have provided their consent for publication of this manuscript.

\section{Competing interests}

None of the authors have stated that they have conflicts of interest.

\section{References}

1. H.T. Arkenau, A. Bermann, K.Rettig, G. Strohmeyer, R.Porschen. 5-Fluorouracil plus leucovorin is an effective adjuvant chemotherapy in curatively resected stage III colon cancer; long-term follow-up results of the adjCCA-01 trials. Annals of Oncology. 2003;14:395-399. https://doi.org/10.1093/annonc/mdg100

2. K Takeda. Clinical development of S-1 for non-small cell lung cancer: a Japanese perspective. Ther Adv Med Oncol. 2013;5(5):301-311. https://doi. 10.1177/1758834013500702

3. H. Yoshioka, I. Okamoto, S. Morita, et al. Efficacy and safety analysis according to histology for S-1 in combination with carboplatin as first-line chemotherapy in patients with advanced non-small-cell lung cancer: updated results of the West Japan Oncology Group LETS study. Annals of Oncology. 2013;24(5):1326-1331. https://doi.org/10.1093/annonc/mds629

4. H Kato, Y Ichinose, M Ohta, E Hata. A Randomized Trial of Adjuvant Chemotherapy with UracilTegafur for Adenocarcinoma of the Lung. N Engl J Med. 2004;350:1713-1721. https://doi.10.1056/NEJMoa032792

5. Shintani $\mathrm{Y}$, Ohta M, Hirabayashi $\mathrm{H}$, et al. Thymidylate synthase and dihydropyrimidine dehydrogenase mRNA levels in tumor tissues and the efficacy of 5-fluorouracil in patients with nonsmall-cell lung cancer. Lung Cancer. 2004;45(2):189-96. https://doi.org/10.1016/j.lungcan.2004.01.015

6. M.Kimura, F.Imamura, T,Inoue, et al. Protein and mRNA expression of folic acid-associated enzymes as biomarkers for the cytotoxicity of the thymidylate synthetase-targets drugs, pemetrexate and S-1, in non-small cell lung cancer. Mol Clin Oncol. 2017;7(1):15-23. https://doi. 10.3892/mco.2017.1262 
7. K.Inoue, M Takao, $\mathrm{F}$ Watanabe, et al. Role of dihydropyrimidine dehydrogenase inhibitory fluoropyrimidine against non-small cell lung cancer - in correlation with the tumoral expression of thymidylate synthase and dihydropyrimidine dehydrogenase. Lung Cancer. 2005;49(1):47-54. https://doi: 10.1016/j.lungcan.2004.12.007.

8. R A Vescio, C H Redfern, T J Nelson, S Ugoretz, P H Stern, R M Hoffman. In vivo-like drug responses of human tumors growing in three-dimensional gel-supported primary culture. PNAS. 1987;84(14):5029-5033. https://doi.org/10.1073/pnas.84.14.5029

9. Furukawa T, Kubota T, R M Hoffman. Clinical Applications of the Histoculture Drug Response Assay. Clinical Cancer Research. 1995;1:305-311. https://pubmed.ncbi.nlm.nih.gov/9815986/

10. Y Fukui, T Oka, S Nagayama, P V. Danenberg, K D. Danenberg, M Fukushima. Thymidylate synthase, dihydropyrimidine dehydrogenase, orotate phosphoribosyltransferase mRNA and protein expression levels in solid tumors in large scale population analysis. Int. J. Mol. Med. 2008;22(6):709-716. https://doi. 10.3892/ijmm_00000076

11. R V.N.Lord, D Salonga, K D.Danenberg,et al. Telomerase reverse transcriptase expression is increased early in the Barrett's metaplasia, dysplasia, adenocarcinoma sequence. J Gastrointestinal Surgery. 2000;4(2):135-142. https://doi.org/10.1016/S1091-255X(00)80049-9

12. N K. Botelho, F I. Schneiders, S J. Lord, et al. Gene expression alterations in formalin-fixed paraffinembedded Barrett esophagus and esophageal adenocarcinoma tissues. Can Biol Ther. 2010;10(2):172-179, https://doi. 10.4161/cbt.10.2.12166

13. J. Matsubara, T. Nishina, Y. Yamada, et al. Impacts of excision repair cross-complementing gene 1 (ERCC1), dihydropyrimidine dehydrogenase, and epidermal growth factor receptor on the outcomes of patients with advanced gastric cancer. Brit J Cancer. 2008;98(4):832-839. https://doi:10.1038/sj.bjc.6604211

14. Y Fukui, T Oka, S Nagayama, P V Danenberg, K D Danenberg, M Fukushima. Thymidylate synthase, dihydropyrimidine dehydrogenase, orotate phosphoribosyltransferase mRNA and protein expression levels in solid tumors in large scale population analysis. Int J Mol Med. 2008; 22(6):709-16. https://doi:10.3892/ijmm_00000076

15. K-J Sohn, F Smirnakis, D N Moskovitz, et al. Effects of folylpolyglutamate synthetase modulation on chemosensitivity of colon cancer cells to 5-fluorouracil and methotrexate. Gut. 2004;53:1825-1831. https://doi. 10.1136/gut.2004.042713

16. R C. Cho, P D. Cole, K-J Sohn, et al. Effects of folate and folylpolyglutamyl synthase modulation on chemosensitivity of breast cancer cells. Mol Cancer Ther. 2007;6(11):2909-2919. https://doi. 10.1158/1535-7163.MCT-07-0449.

17. B I. Schweitzer, A P. Dicker, J R. Bertino. Dihydrofolate reductase as a therapeutic target. FASEB J. 1990:2441-2452; https://doi. 10.1096/fasebj.4.8.2185970

18. Y Konishi, R Kanamaru, C Ishioka, et al. The changes in the levels of dihydrofolate reductase mRNA and its gene dosage in 5-fluorouracil-resistant L1210 cells. Tohoku J Exp Med. 1990;161(1):33-42. https://doi.org/10.1620/tjem.161.33 
19. P V. Danenberg, B Gustavsson, P Johnston, et al. Folates as adjuvants to anticancer agents: Chemical rationale and mechanism of action. Crit Rev Oncology Hematol. 2016;106:118-131. https://doi.org/10.1016/j.critrevonc.2016.08.001

20. Eguchi K, Oyama T, Tajima A, et al. Intratumoral gene expression of 5-fluorouracil pharmacokineticsrelated enzymes in stage I and II non-small cell lung cancer patients treated with uracil-tegafur after surgery: a prospective multi-institutional study in Japan. Lung Cancer. 2015;87(1):53-8. https:// doi: 10.1016/j.lungcan.2014.10.013.

21. J Nakano, C Huang, D Liu, et al. Evaluations of biomarkers associated with 5-FU sensitivity for nonsmall-cell lung cancer patients postoperatively treated with UFT. Brit J Cancer. 2006;95:607-615. https://doi. 10.1038/sj.bjc.660329

22. PP Grimminger, PM Schneider, R Metzger, et al. Low thymidylate synthase, thymidine phosphorylase, and dihydropyrimidine dehydrogenase mRNA expression correlate with prolonged survival in resected non-small-cell lung cancer. Clin Lung Cancer. 2010;11(5):328-34.

https://doi.org/10.3816/CLC.2010. n. 041

23. Y Ishikawa, T Kubota, Y Otani, et al. Dihydropyrimidine Dehydrogenase and Messenger RNA Levels in Gastric Cancer: Possible Predictor for Sensitivity to 5-Fluorouracil. Jpn J Cancer Res. 2000;91(1):105112. https:// doi. 10.1111/j.1349-7006.2000.tb00866.x.

24. D. Edler, B. Glimelius, M. Hallström, A. Jakobsen, P. G. Johnston, I Magnusson囚Thymidylate Synthase Expression in Colorectal Cancer: A Prognostic and Predictive Marker of Benefit from Adjuvant Fluorouracil-Based Chemotherapy. J Clinical Oncology. 2002;20(7):1721-28. https://doi. org/10.1200/JC0.2002.07.039

25. 25 W Ichikawa, H Uetake, Y Shirota, et al. Both gene expression for orotate phosphoribosyltransferase and its ratio to dihydropyrimidine dehydrogenase influence outcome following fluoropyrimidine-based chemotherapy for metastatic colorectal cancer. Brit J Cancer. 2003;89:1486-1492. https://doi.org/10.1038/sj.bjc.6601335

26. M Takeda, I Okamoto, N Hirabayashi, M Kitano, K Nakagawa. Thymidylate synthase and dihydropyrimidine dehydrogenase expression levels are associated with response to S-1 plus carboplatin in advanced non-small cell lung cancer. Lung Cancer. 2011;73(1):103-109. https://doi.org/10.1016/j.lungcan.2010.10.022

27. T Takechi, H Okabe, K Ikeda, et al. Correlations between antitumor activities of fluoropyrimidines and DPD activity in lung tumor xenografts. Oncology Reports. 2005;14(1):33-39. https://doi.org/10.3892/or.14.1.33

28. M.W. Saif, L.S. Rosen, K. Saito, C. Zergebel, L. Ravage-Mass D.S. Mendelson. A Phase I Study Evaluating the Effect of CDHP as a Component of S-1 on the Pharmacokinetics of 5-Fluorouracil. Anticancer Research. 2011;31:625-632. https://doi. 0250-7005/2011\$2.00+.40

29. T Yoshimasu, S Oura, F Ohta, S Hashimoto, M Kawago, Y Okamura. Epidermal Growth Factor Receptor Mutations Are Associated with Docetaxel Sensitivity in Lung Cancer. J Thoracic Oncology. 2011;6(10):1658-1662. https://doi. org/10.1097/JTO.0b013e318221f71a 
30. M Tanahashi, H Niwa, H Yukiue, E Suzuki, H Haneda, N Yoshii. Adjuvant Chemotherapy Based on the In Vitro Histoculture Drug Response Assay for Non-small Cell Lung Cancer Improves Survival. $J$ Thoracic Oncology. 2010;5(9):1376-1381. https://doi.org/10.1097/JT0.0b013e3181e7d035

31. T. Ohashi, T. Yoshimasu, S. Oura, et al. Class III Beta-tubulin Expression in Non-small Cell Lung Cancer: A Predictive Factor for Paclitaxel Response. Anticancer Research. 2015;35:2669-2674. https://doi. 0250-7005/2015 $\$ 2.00+.40$

32. T Kubota, N Sasano, $\mathrm{O}$ Abe, et al. Potential of the histoculture drug-response assay to contribute to cancer patient survival. Clinical cancer research. 1995;1(12):1537-43. https://doi:pubmed.ncbi.nlm.nih.gov/9815954/

33. Y S Yoon, C W Kim, S A Roh, rt al. Applicability of Histoculture Drug Response Assays in Colorectal Cancer Chemotherapy. Anticancer Research. 2012;32:3581-3586. http://ar.iiarjournals.org/content/32/8/3581.full.pdf+html

34. T Nakajima, K Yasufuku, M Suzuki, et al. Thymidylate Synthase, Dihydropyrimidine Dehydrogenase, Thymidine Phosphorylase, Orotate Phosphoribosyltransferase mRNA Expression in Lung Cancer Metastatic Lymph Node Samples Obtained by Endobronchial Ultrasound-Guided Transbronchial Needle Aspiration - A Pilot Study. Clin Lung Cancer. 2011;12(5):293-97. https://doi.org/10.1016/j.cllc.2011.06.001

\section{Tables}

Due to technical limitations, table 1 is only available as a download in the Supplemental Files section.

\section{Figures}




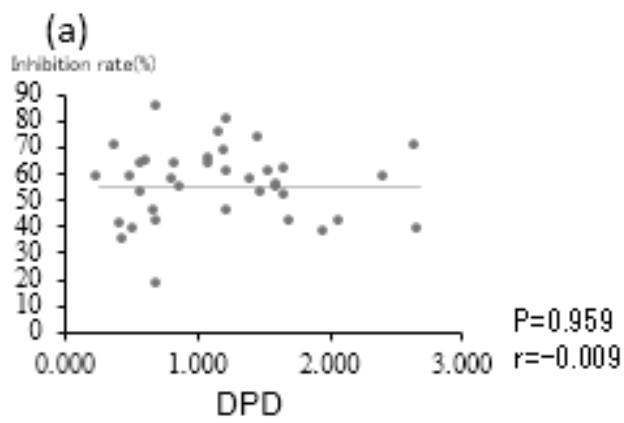

(b)

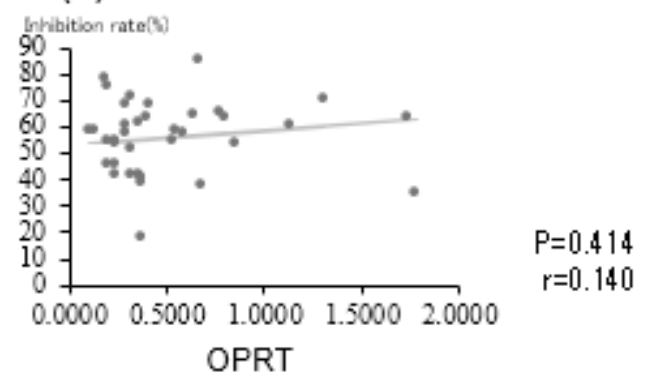

(c)

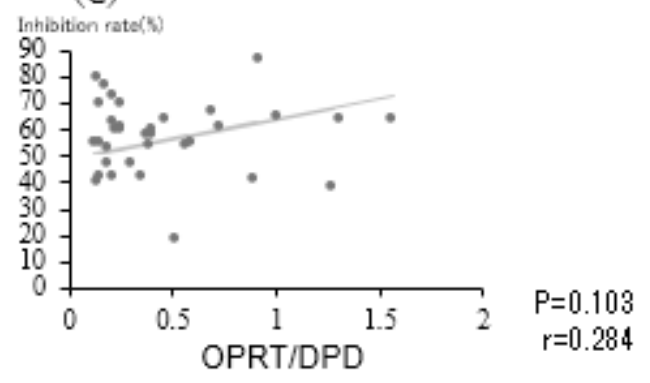

Figure 1

No significant correlation was found between expression of DPD (a), OPRT (b), and DPD/OPRT (c) and the percent inhibition with 5-FU using the HDRA method. 


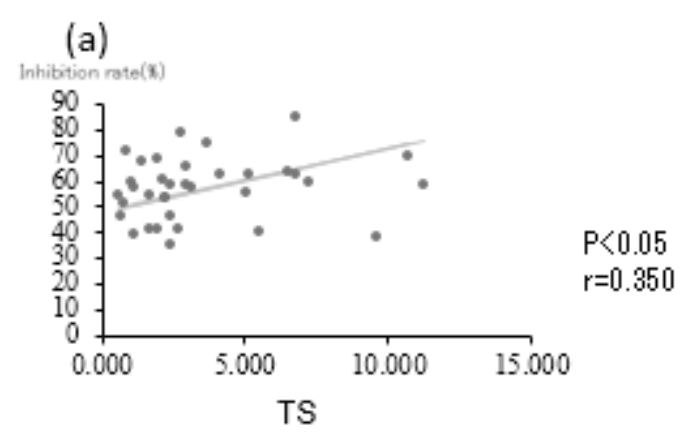

(b)

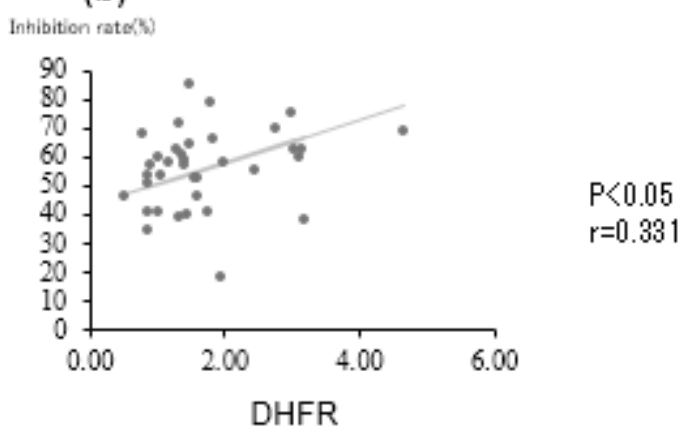

(c)

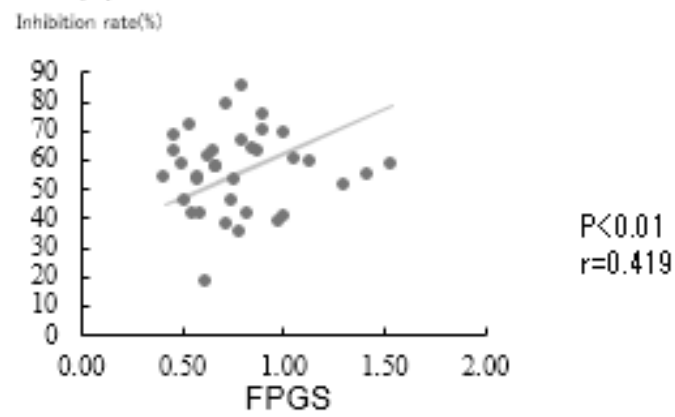

Figure 2

A significant correlation was found between expression of TS (a), DHFR (b), and FPGS (c) and the percent inhibition with 5-FU using the HDRA method.

\section{Supplementary Files}

This is a list of supplementary files associated with this preprint. Click to download.

- SakonsArti.Table1.pptx 